КРАСОВСКАЯ Наталия Рудольфовна - кандидат психологических наук, Аппарат Государственной Думы ФС РФ (125007, Россия, г. Москва, ул. Охотный ряд, 1; goulina@gmail.com)

\title{
ЭТНОКУЛЬТУРНАЯ ИДЕНТИЧНОСТЬ
}

\begin{abstract}
Аннотация. В статье анализируется понятие «этнокультурная идентичность» в современной науке. Основные вызовы современности - это глобализация и влияние глобальных процессов на формирование этнокультурной идентичности. Соответственно, возрастает и число теорий этнокультурной идентичности, к которым можно отнести теории объективизма, инструментализма, конструктивизма, этносимволизма, этничности. Автор исследует влияние глобализации на кризис идентичности, выясняет причины его возникновения, а также возможные способы и пути его преодоления. Важнейшим методом исследования проблемы этнокультурной идентичности является сравнительный метод. Сравнению подлежат различные концепции этнокультурной идентичности, а также три ее системы: этноцентричная, полицентричная и метацентричная.
\end{abstract}

Ключевые слова: этнокультурная идентичность, этнос, этнокультура, глобализация, идентификация, этноцентризм, полицентризм, метацентризм

\section{Введение}

Понятие «этнокультурная идентичность» возникло сравнительно недавно, в последние десятилетия. Известный американский социолог, психолог и психоаналитик, создатель термина «кризис идентичности» Э. Эриксон понимал идентичность как процесс и результат личностного развития, имеющий связь с социальной адаптацией личности. Формулируя понятие «кризис идентичности», Э. Эриксон полагал, что человек формирует свою идентичность путем создания собственной убедительной картины мира и своего места в нем. Сегодня это понятие широко используется в философии, психологии, этнологии, политологии, культурной и социальной антропологии с разными значениями и в разных контекстах. Однако, несмотря на активную разработку в современных научных теориях проблемы идентичности, существует множество интерпретаций этого понятия, что свидетельствует о сложности явления. «В самом общем понимании оно означает осознание принадлежности объекта (субъекта) другому объекту (субъекту) как части и целого, особенного и всеобщего» [Садохин, Грушевицкая 2000]. Главными характерными признаками и основаниями понятия «идентичность» являются тождественность, одинаковость, совпадение. Идентификация - отождествление, уподобление, приравнивание. В психологии и социологии - это «категория, отражающая процесс и результат эмоционального и иного совпадения индивида с другим человеком, группой, образцом или идеалом» [Михайлова 2013]. В рамках психологических теорий идентичность связывается со способностью индивида оставаться самим собой в изменяющихся социальных ситуациях и с осознанием индивидом самого себя в качестве человеческой личности, отличающейся от других [Широкогоров 2012]. В социальной психологии идентификация - это отождествление индивидом себя с другим человеком, непосредственное переживание субъектом той или иной степени своей тождественности с объектом. По мнению А.М. Монакова, «идентификация - это эмоционально оформленный процесс самоотождествления индивида, группы с другим человеком, группой или образцом, интериоризации занимаемых социальных статусов и освоения значимых социальных ролей» [Монаков 2008].

Ввиду сложного, многоаспектного характера этого явления в современной научной литературе понятия «национальная идентичность», «этнокультурная идентичность», «этническая идентичность», «гражданская идентичность» часто употребляются как синонимы. Однако, по мнению М.К. Поповой, эти понятия 
отличаются друг от друга. Рассматривая проблему национальной идентичности, она говорит о двух ее составляющих: гражданско-правовой и этнокультурной [Попова 2004]. Некоторые исследователи разграничивают такие понятия, как этническая и культурная идентичность, рассматривая первую как «осознание своей принадлежности к определенной этнической общности с позиций генетического, кровного родства, общности территории», а вторую - как «осознание принадлежности к данной (этнической, национальной, региональной) общности на основании, в первую очередь, культурных характеристик последней; осознанное принятие культурных “образцов” " [Шарапова 2005]. Однако при всем многообразии определений понятия «идентичность» и подходов к его рассмотрению все исследователи выделяют один общий момент. Идентичность позволяет людям выделить свою этническую общность («Мы») и других («Они») и одновременно ощущать свою принадлежность к данной общности. В методологическом плане интересным является определение идентичности, предложенное В.А. Ачкасовым, - «символическое средство объединения с одними и дистанцирования от других» [Ачкасов 1999].

\section{Критерии этнокультурной идентичности}

Сравнительно-историческое сравнение имеет важное значение для когнитивного изучения идентичности. Необходимы знания о критериях этнокультурной идентичности, благодаря которым общественная группа приобретает специфические признаки, отделяющие ее от других групп.

Под этнокультурной идентичностью мы будем понимать осознание своей принадлежности к той или иной этнической общности на основании общей территории проживания, устойчивых особенностей культуры и языка. Таким образом, выделяются три основных критерия этнокультурной идентичности: территориальный, культурный и языковой.

Современная культура характеризуется тем, что, с одной стороны, стираются различия между этносами, между индивидами, что приводит к возникновению кризиса идентичности, а с другой - наблюдается и процесс сохранения, и более того - рост этнического самосознания в связи с социальными трансформациями, что является основой формирования этнокультурной идентичности. Существует множество направлений, решающих вопросы определения этнической идентификации личности, исходя из возможностей различных дисциплин и методологий. Перед наукой встает вопрос выбора научного направления, занимающегося проблемами идентичности. Подобная множественность направлений вызвана важностью, сложностью и многоаспектностью самого явления, неоднозначной трактовкой самого понятия. Этнокультурная идентичность является центральной категорией этносоциологии, а также изучается другими смежными науками: антропологией, этнологией, социологией и др.

\section{Кризис этнокультурной идентичности}

Кризис этнокультурной идентичности имеет различные причины. Одной из главных является вынужденное переселение больших масс людей на другие территории и в другие государства. К этой же причине можно отнести и добровольную миграцию людей. Подобное сейчас происходит с Европой. В страны ЕС, особенно в Германию, устремились волны беженцев и мигрантов с Ближнего Востока и из Северной Африки. Тема кризиса этнокультурной идентичности среди вынужденных беженцев и переселенцев является весьма актуальной в наше время и требует изучения.

Другой причиной кризиса этнокультурной идентичности является однобокое поведение правящей верхушки, высших классов государственных служащих, 
специалистов и ведущих основных СМИ. В СССР данные категории людей развивали и пропагандировали советскую идентичность, во многом враждебную отдельным этнокультурным идентичностям, которые развивались вопреки государственной пропаганде и культуре. Так, например, в 70-е гг. XX в. в СССР стал набирать силу зачастую скрытый интерес к православию и православной культуре, в какой-то мере способствуя пробуждению дальнейшего интереса и попыткам возрождения культуры и ритуалов царского периода.

Современная глобализация позволяет развиваться поверхностному стиранию кризисных явлений этнокультурной идентичности, однако на самом деле она только искажает процессы прохождения кризиса, деформируя в сознании большинства потребности, обусловленные этнокультурной принадлежностью. Со временем деформация данных потребностей грозит реализоваться в форме социокультурных стрессов. Существует множество вопросов, требующих ответа: 1) каковы причины роста национального самосознания, обусловливающего формирование этнокультурной идентичности в наше время; 2) почему именно этнические общности часто оказываются наиболее активными в ситуации острой социальной нестабильности; 3) какие инструменты используются для поддержания позитивной этнокультурной идентичности.

Кризис этнокультурной идентичности может быть также спровоцирован изменениями гендерных стереотипов в обществе. Повышение роли женщин в социальной жизни, их занятость на работе и высокая заработная плата, а также популярность среди женщин видов спорта, которые ранее считались мужскими, - бокса, хоккея и др., - эти и другие гендерные стереотипы меняются достаточно быстро в современном мире. Все более популярным становится «шведский» вариант гендерного взаимодействия. Роли мужчины и женщины в семейной и социальной жизни стремятся к выравниванию, что также ломает прежние гендерные стереотипы о превосходстве мужчины в общественной и семейной жизни.

Человеку всегда необходимо быть частью коллектива, и этнос отнюдь не единственная группа, в осознании родства с которой человек ищет опору в жизни. Среди таких групп можно назвать политические партии, религиозные общины, профессиональные союзы, субкультуры молодежи и др. Подобные группы оказываются аморфными и неустойчивыми, поскольку их состав постоянно обновляется, сроки их существования ограничены во времени, самого человека могут за какой-то проступок из группы исключить. Именно всех этих недостатков лишена этническая общность: она устойчива во времени, для нее характерна стабильность состава, каждый человек обладает устойчивым этническим статусом, его невозможно «исключить» из этноса. Этнокультурная идентичность одна из важнейших идентичностей личности, которая выражается в осознании своей принадлежности к определенной этнической общности. Данная идентичность имеет большое значение в экономически слабо развитых обществах, в современном развитом обществе этот вид идентичности сегодня приобретает новые формы.

\section{Значение этнокультурной идентичности}

Идентичность помогает выделить две разные общности: «себя» и «их». Она подобна средству объединения с одними и дистанцирования от других [Ачкасов 1999]. Идентичность очень важна тем, что создаются основания, объединяющие членов группы и позволяющие ей отмежеваться от других групп. Общая территория проживания, особенности языка и культуры, национальная принадлежность сейчас определяют этнокультурную идентичность. Поэтому можно 
выделить четыре основных способа определения этнокультурной идентичности: языковой, территориальный, национальный, культурный.

Стабильность является одной из самых значимых ценностей для общества. Поэтому, когда разрушается социальная система и мировоззрение, которые объединяли общество, люди обращаются к этнокультурной идентичности. Значение этнокультурной идентичности повышается в условиях социальной нестабильности. Характерно, что этот процесс во многих странах расширяется. Следовательно, значение этнокультурной идентичности увеличивается. Например, в современных США между группами с различной этнокультурной идентичностью возникают противоречия, которые находят свое проявление в различных сферах. Так, Э. Кауфман, описывая развитие «белой» этнокультурной идентичности, считает, что в эту этнокультурную группу входят и представители населения США, родившиеся от смешанных браков, к которому относится и он сам [Kaufmann 2019]. При этом следует отметить, что его взгляды подвергаются критике как в самих США, так и за их пределами.

Этнокультурная идентичность рождается с появлением национальной культурной элиты. Этнокультурная идентичность изменчива. Современные СМИ и Интернет играют важную роль в процессе формирования этнокультурной идентичности. Человек вполне способен стать пассивным потребителем ценностей, которые пропагандируются представителями культурной элиты. В структуре этнокультурной идентичности можно выделить такие элементы, как поведенческий, эмоциональный и когнитивный. Исследователи приходят к выводу, что наиболее значимым является когнитивный элемент (представления об особенностях собственной группы и отношение к членству к ней).

В процессе формирования этнокультурной идентичности особую роль играет язык. Это особенно важно в условиях эмиграции и иммиграции граждан в другие страны. В современном обществе полное овладение другими языками имеет большое влияние на формирование этнокультурной идентичности [Denisova et al. 2019].

\section{Типы этнокультурной идентичности}

Сравнительный анализ дает преимущество в исследовании этнокультурной идентичности. Так, осознание принадлежности человека к какому-либо народу во многом зависит от того, живет ли он в однонациональной или многонациональной среде. Интенсивное межнациональное общение дает человеку больше шансов для приобретения знаний о собственной группе и других национальных группах, способствует формированию коммуникативных умений. Отсутствие опыта межнационального общения приводит к меньшему числу подобных контактов и выражается в меньшей степени интереса к собственной национальности.

Развитие радио, телевидения, компьютерные технологии внесли гигантский вклад в развитие современного общества. В условиях глобализации в современном мире более широкое применение находит интегративный подход, который позволяет исследовать изменения в отношениях между Востоком, где очень развито национальное самосознание, и Западом, где превалирует самосознание гражданское. Такой подход очень актуален в России, где в силу огромных масштабов страны присутствуют оба варианта, что может помочь решать проблемы межнационального общения в многонациональной стране и дать научную основу для поддержания процессов формирования положительной этнокультурной идентичности.

В современных научных исследованиях весьма эффективным методом является метод сравнительного анализа. Сравнительный анализ применяется в т.Ч. 
для сравнения различных концепций, методов и способов исследования этнокультурной идентичности.

В современном мире, очевидно, проявляются две противоречивые тенденции развития цивилизации. С одной стороны, идет процесс создания глобальных структур, а с другой - процесс сегментации мира. И как только усиливается одна тенденция, то одновременно активизируется и другая. Эти противоречия в условиях существования современной цивилизации являются значимым фактором в развитии этнокультурной идентичности. Процесс сохранения существующих наций свидетельствует, что этнос в условиях глобализации и модернизации получает определенные дополнительные импульсы для развития и сохранения своей самобытности [Кессиди 2003]. Основные вызовы современности - это глобализация и влияние глобальных процессов на формирование этнокультурной идентичности. Соответственно, возрастает и число теорий этнокультурной идентичности, к которым можно отнести теории объективизма, инструментализма, конструктивизма, этносимволизма, этничности.

Теория объективизма основана на утверждении, что самыми главными являются этнические черты, которые являются неизменными. Этнические биологические и социальные черты, тем не менее, постепенно меняются в глобализирующемся мире. Миграционные, межэтнические процессы показывают, что этнические сообщества не являются неизменными и обособленными образованиями [Широкогоров 2012].

Инструменталистский подход рассматривает народ как результат политических мифов, создаваемых и используемых элитами в стремлении к власти. Этнокультурную идентичность здесь рассматривают как индикатор социальной мобильности. Люди сознательно мобилизуют политические и этические символы ради оформления своего этноса. Этнос с позиции данного подхода это результат мобилизации элитами социальных групп.

В рамках конструктивистской теории народ описывается как объект, обладающий определенным набором социально-психологических черт. Этническая самоидентификация формирует субъективный статус, который может не совпадать с объективным статусом этнической принадлежности. Учитывая многообразие и большую систему этнических сообществ, человек может самоидентифицироваться одновременно с несколькими из них.

Также выделяют три типа этнической идентичности: этноцентрическую, полиэтническую, метаэтническую. Этноцентрическая идентичность означает восприятие и оценку чужих обычаев и традиций через призму собственной этнической группы. Одновременно этноцентризм предусматривает признание превосходства своей культуры над другими культурами. Полиэтническая идентичность признает равноценными несколько этносов и их культур. Такая идентичность характерна, например, для жителей Швейцарии. Для российского Северного Кавказа элементы полиэтнической этнокультурной идентичности не менее актуальны. Через прозу и поэзию, например, адыгских и карачаевских поэтов и писателей современные исследователи находят общие черты их этнокультурной идентичности [Betuganova et al. 2019]. Метаэтизм менее распространен. Человек относит себя ко всему человечеству, выходит на сверхэтнический уровень и считает себя гражданином мира.

\section{Заключение}

Процессы формирования этнокультурной идентичности в современном мире происходят разными путями и имеют различный характер. Особенности их в большой степени обусловлены моно- или полиэтническим характером государства. В полиэтнических странах одновременно идет формирование граждан- 
ской и этнокультурных идентификаций. Оптимальной политикой поддержания процесса формирования позитивной этнокультурной идентичности является принятие всех позиций существующих идентификационных моделей и работа по смягчению возможных конфликтов в процессе формирования идентичности через механизм сдержек и противовесов в обществе [Dunaev, Kurganskaya, Shaikemelev 2019]. Кризис этнокультурной идентичности приводит к повышению напряжения между государством и обществом, а его разрешение дает свои плоды при последующем развитии общества.

В настоящее время существует множество сценариев дальнейшего развития человечества. Большинство из них в скрытой или явной форме формулируют идею, что человечество будет развиваться в многополярном мире [Denisova et al. 2019], что делает дальнейшее исследование этнокультурной идентичности важным научным направлением.

\section{Список литературы}

Ачкасов В.А. 1999. Этническая идентичность в ситуациях общественного выбора. - Журнал социологии и социальной антропологии. Т. 2. Вып. 2. С. 56-68.

Кессиди Ф.К. 2003. Глобализация и культурная идентичность. - Bonросы философии. № 1. С. 78-86.

Михайлова М.А. 2013. Этнокультурная идентичность в условиях культурной глобализации. - Вестник Бурятского государственного университета. № 14. С. 191-196.

Монаков А.М. 2008. Этнос и этническая идентичность. - Вестник Московского университета. Сер. 12. Философия. № 1. С. 84-92.

Попова М.К. 2004. Национальная идентичность и ее отражение в художественном сознании. Воронеж: Воронежский гос. ун-т. 169 с.

Садохин А.П., Грушевицкая Т.Е. 2000. Этнология: учебник для студентов высших учебных заведений. М.: ИЦ «Академия»; Высшая школа. 304 с.

Шарапова С.М. 2005. Феномен идентичности в истории профессиональной художественной культуры коми (зырян) ХХ века: автореф. дис. ... к.культурологии. СПб. 27c.

Широкогоров С.М. 2012. Этнос: исследование основных принципов изменения этнических и этнографических явлений. 3-е изд. М.: ЛИБРОКОМ. 134 с.

Betuganova Y.N., Uzdenova F.T., Dodueva A.T., Khubolov S.M. 2019. Problem of National Identity and Ways of Its Resolution in Works of Adyghe and KarachayBalkarian Authors. - Tarih Kültür ve Sanat Araștırmaları Dergisi (Journal of History Culture and Art Research). Vol. 8. No. 2. P. 660-670.

Denisova G., Denisova A., Litvinenko E., Susimenko E. 2019. The Roles of Language and Ethnocultural Identity in Integrating Immigrant Youth in Southern Russia. International Journal of Inclusive Education. URL: https://www.researchgate.net/publication/334709248_The_roles_of_language_and_ethnocultural_identity_in_integrating_immigrant_youth_in_southern_Russiä (accessed 25.05.2020).

Dunaev V., Kurganskaya V., Shaikeme-ev M. 2019. Identity Politics in Managing the System Risks of Nation-Building: On the Example of the Republic of Kazakhstan. Baltic Journal of European Studies. Vol. 9. Is. 1(26). P. 99-114.

Kaufmann E. 2019. White Identity and Ethno-Traditional Nationalism in Trump's America. - Forum. Vol. 17. Is. 3. P. 385-302. 
KRASOVSKAIA Nataliya Rudol'fovna, Cand.Sci. (Psych.), Office of the State Duma of the Federal Assembly of the Russian Federation (1 Okhotny Ryad St, Moscow, Russia, 125007, goulina@gmail.com)

\title{
ETHNOCULTURAL IDENTITY
}

\begin{abstract}
The author analyzes the concept of ethnocultural identity in the modern science. The main challenges of our time are globalization and the influence of global processes on the formation of ethnocultural identity. Correspondingly, the number of theories of ethnocultural identity is also growing, and includes theories of objectivism, instrumentalism, constructivism, ethno-symbolism, and ethnicity. The article studies the influence of globalization on the identity crisis. The author clarifies reasons for its occurrence, as well as possible ways and means of overcoming it. The most important method of studying the problem of ethnocultural identity is the comparative method. Different concepts of ethnocultural identity are becoming a subject for comparison, as well as its three systems: ethnocentric, polycentric and metacentric ones. Keywords: ethnocultural identity, ethnos, ethnoculture, globalization, identification, ethnocentrism, polycentrism, metacentrism
\end{abstract}

РЫБКИНА Ольга Сергеевна - кандидат политических наук, доцент кафедры государственного управления и менеджмента Нижегородского института управления - филиала Российской академии народного хозяйства и государственной службы при Президенте РФ (603950, Россия, г. Нижний Новгород,nр-кт Гагарина, 46; olya_07@mail.ru)

\section{НЕКОТОРЫЕ АСПЕКТЫ РАЗВИТИЯ СИСТЕМЫ МЕСТНОГО САМОУПРАВЛЕНИЯ В КРУПНЫХ ГОРОДСКИХ АГЛОМЕРАЦИЯХ: ТРАНСПОРТНАЯ ПРОБЛЕМА И ПЕРСПЕКТИВЫ ЕЕ РЕШЕНИЯ}

\begin{abstract}
Аннотация. В статье рассматриваются вопросы реорганизации системы общественного транспорта в российском городе-миллионнике. Автор уделяет преимущественное внимание управленческим и политическим аспектам, делает выводы относительно путей снижения остроты транспортной проблемы в Нижнем Новгороде, а также относительно изменения общественных пространств в данном мегаполисе. B статье отмечается важная роль $P R$-сопровождения мероприятий, которые необходимо осуществлять городской власти, и обозначен ряд вопросов, которые должны быть решены муниципальными властями в тесном сотрудничестве с горожанами.
\end{abstract}

Ключевые слова: общественный транспорт, проблемы, мегаполис, партиципация, политические аспекты, лоббизм, координация, финансирование

$\mathrm{T}$ ранспортная проблема в современных отечественных мегаполисах является одной из важнейших, а потому имеет большое политическое значение [Халин 2013: 52]. Связано это не только с социальной политикой (это очевидно!) [Пахомова, Чернева 2016: 171] и финансовыми вопросами, но равно и с рядом иных значимых аспектов. В полной мере это касается и муниципального образования Нижний Новгород, уже давно являющегося не только городоммиллионником, но и городской агломерацией с интенсивно увеличивающимися транспортными потоками.

Наиболее значимые транспортные проблемы Нижнего Новгорода можно охарактеризовать следующим образом. Во-первых, за последние полтора десяти- 